\title{
Influencias y estilo, en la obra de fray Manuel Navarrete
}

\begin{abstract}
A Ungue fray Manuel Navarrete poseía eminentes dotes poéticas, como la sencillez de la expresión, la viveza y la ternura de los afectos, la lozanía y amenidad risueña de la fantasía, sin embargo, muchas de sus poesías carecen de originalidad. Esto no parece favorecer al poeta; mas debemos recordar que Navarrete vivió en una época de imitación y que, por lo tanto, no hizo más que seguir los gustos de su tiempo y las huellas de sus colegas.
\end{abstract}

A mediados del siglo xviII se encuentran en España dos diferentes grupos de poetas: "El primer grupo se distingue por el espíritu castizo y por la pureza de lenguaje, cuyos representantes más elevados son Nicolás Fernández de Moratín, Iglesias de la Casa y fray Diego González; el segundo grupo caracterizado por la tendencia didáctica, con bastante prosaísmo en la forma, representado por Luzán, Forner, Marchena y otros.

"El espíritu crítico y filosófico que se va desarrollando a medida que avanza el siglo, se extiende a la poesía y culmina en el último tercio con Jovellanos, Meléndez Valdés y Alvarez de Cienfuegos". ${ }^{1}$

De estos dos grupos tomó Navarrete sus modelos, así como también de poetas de la época precedente. ${ }^{2}$

Meléndez Valdés, representante en España de la influencia clásica francesa, fué su modelo favorito. "En ambos se advierte el mismo estilo, escuela y sabor literario, aunque no obtuvieron igual éxito en los géneros que cultivaron". ${ }^{3}$ Meléndez, en los géneros cortos, especialmente en los romances y anacréonticas, adquirió una perfección no conocida hasta entonces, mientras que "Navarrete con20 
quistó sus lauros en las odas que respiran la dulce filosofía, melancolica ternura y grandiosa elevación" ; ${ }^{4}$ esto es, en el género templado, filosófico y religioso.

Meléndez empezó a formar su musa en los modelos de la anti-... gua lírica española, junto con Iglesias, fray Diego González y otros miembros de la escuela salmantina. Efectivamente, en los primeros versos de Meléndez hay perfecta imitación de fray Luis de León, Villegas y otros muchos. Pero luego, animado por Jovellanos, se dedicó a cultivar otras formas diversas, levantándose a veces a regiones de la poesía elevada, sin abandonar sus géneros predilectos: bucólico, pastoril y anacreóntico.

La influencia de Meléndez se nota casi en toda la obra de Navarrete, en la forma, metros, argumentos y aun en los títulos de sus composiciones, pues son idénticos algunos, como "Muerte de Filis", "Ausencia de Clori"; otros difieren algo, como "La pollita de Clori" de Navarrete, que consta de once odas y "Ia paloma de Filis" de Meléndez, que tiene catorce. Navarrete canta a la "Tortolilla", y ambos lamentan igualmente la ausencia de Clori.

Contraste singular presentan "La tarde" del poeta salmantino y "La mañana" del bardo mexicano. Tomando aquélla como modelo, lleva a cabo el contraste con ingenio y habilidad, no sólo en el título sino en las ideas y en las frases. Veamos los versos iniciales de cada una de estas composiciones:

\section{LA TARDE}

Ya el Héspero delicioso

Entre nubes agradables

Cual precursor de la noche

Por el occidente sale;

Do con su fúlgido brillo

Deshaciendo mil celajes,

A los ojos se presenta

Cual un hermoso diamante. ${ }^{5}$

$$
\text { La Mafinana }
$$

Ya se asoma la cándida mañana

Con su rostro apacible; el horizonte

Se baña de una luz resplandeciente

Que hace brillar la cara de los cielos. ${ }^{6}$ 
En la primera, Héspero, la estrella de la tarde precursora de la noche, sale por el occidente deshaciendo mil celajes.

En la segunda, la plácida mañana se asoma bañando el horizonte de luz resplandeciente.

Meléndez continúa la descripción de la tarde: las sombras se apoderan del valle y la tarde queda en poder de las tinieblas. Las aves vuelan a sus nidos; el labrador suelta los cansados bueyes; los zagales vuelven al redil; el universo entero se abandona al sueño y al reposo; todo es paz, silencio y soledad. De igual modo, Navarrete describe la mañana: las tinieblas huyen ante el albo dia que derrama placer por todo el mundo; su vital ambiente restaura los seres que hermosean la tierra; la naturaleza entera despierta; todo se pone en movimiento. Cada uno comienza su tarea; los pastores, tras sus ovejas; los vaqueros, tras sus ganados; el labrador se dispone a cultivar la fértil tierra; huyen las fieras a sus cuevas; brincan las cabras; balan los corderos; mugen los toros; todo es vida $\mathrm{y}$ animación.

Aunque Navarrete procuró copiar fielmente su modelo, se encuentra gran diferencia entre los dos poetas. Esto, tal vez, es debido al motivo o móvil que los inspira. "Meléndez estimaba la poesía comó un instrumento de reforma social, como vehículo de altos pensamientos morales y físicos, como medio indirecto de educación más que como arte puro y libre", ${ }^{7}$ mientras que Navarrete cultivaba el arte por particular inclinación, tan sólo por entretenerse con las musas. Por esto, fray Manuel es más feliz en las composiciones originales, donde se deja llevar de su imaginación y de sus sentimientos personales.

Otro de los modelos de Navarrete es el presbítero José Iglesias de la Casa, ${ }^{8}$ distinguido especialmente como autor de epigramas $y$ letrillas satíricas. Fray Manuel parece haber imitado no sólo el argumento, sino asimismo el metro de la siguiente oda anacreóntica de Iglesias:

Durmiendo yo a la sombra de unas frondosas vides soñé que Egón los brazos gozaba de mi Nise. Yo entonces, entre sueños, incorporarme quise 
a vengar con su muerte mis celos insufribles. Pero desperté en esto $\mathrm{y}$ al ver sola a mi Nise, reclinado en su seno volví luego a dormirme. 9 Cortó un cabello Nise de sus doradas trenzas y con él ambas manos me ligaba halagüeña. Yo me rei creyendo que fácil cosa fuera quebrantar las lazadas con que abrazarme intenta. Mas después lloré triste, cuando al querer romperlas, aquel blando cabello le hallé dura cadena.

Oda de Navarrete:

a unos cabelios de Celia

Lucientes hilos de oro que como hermosos rayos fuisteis en otro tiempo del sol en que me abraso. Ahora por efecto de amor atáis mis manos como blandas cadenas, o como dulces lazos. Dejadme una $y$ mil veces cual cautivo besaros, $\mathrm{y}$ adoraros rendido dichoso amante a todo. ¡Oh! quiera el alto cielo que interminables años duren estas prisiones, en que alegre me hallo. ¡Oh cortísima vida para un amor tan largo! i ay!, ámame, mi Celia, ámame, como te amo. 
Tambiẻn a Nicasio ${ }^{10}$ Alvarez de Cienfuegos ${ }^{11}$ se propuso imitar Navarrete. Este poeta, que se creyó clásico y se ufanaba por . serlo, dista mucho en su gusto del verdadero clasicismo, "especialmente en las llamadas traducciones, que con nombres de tales son paráfrasis muy desviadas de los originales ciertamente". Si Cienfuegos hubiera vivido en otro siglo, sin duda habría sido romántico. "El valor verdadero de Cienfuegos consiste en que en medio de aquella glacial atmósfera de amaneramiento y artificio que habian creado los poetas reformadores, escribe lo que siente y siente con ímpetu y firmeza". ${ }^{13}$ En lo último es en lo que fray Manuel imita a su modelo con gran fidelidad. Ambos poetas escribieron con tal sencillez y sinceridad, que al leer sus obras, no puede uno menos que ver reflejada en ellas, con candor, el alma que las animaba, percibiendo como a través de claro cristal, sus anhelos, sus inclinaciones y sus más íntimos sentimientos.

Asimismo en la poesías de fray Manuel Navarrete se encuentra cierta semejanza con los versos de fray Diego González, uno de los caracteres más puros que han dado lustre al claustro y a las letras. "Su corazón tierno y delicado había nacido únicamente para amar, para amarlo todo. Dios, la mujer y la humanidad se disputaban su alma. Dios triunfó de todos los impulsos humanos." ${ }^{15} \mathrm{Ob}-$ tuvo González su mayor éxito, en el género festivo. En este género usó cuantos giros felices y agraciados encierra el lenguaje poético. Aunque fray Diego González admiraba e imitaba a Horacio, su modelo favorito fué fray Luis de León, en cuya imitación fué tan feliz que "al leer sus odas y algunas versiones de los salmos, nos parece oír la solemne entonación de su gran maestro". ${ }^{16}$ Fray Diego González tuvo singular influencia sobre el lenguaje de Navarrete. Ambos autores usan generalmente un lenguaje bastante copioso, sin alarde ni esfuerzo alguno; prueba evidente de que el gusto y el estilo de ambos se habían formado exclusivamente con la lectura de los poetas latinos y los antiguos castellanos. Las composiciones de estos dos autores se caracterizan por la decencia y la ternura. Ambos parecen inspirados por el ángel de los castos amores.

No satisfecho con los autores ya mencionados, quiso Navarrete aumentar la variedad de sus modelos imitando a uno de los grandes fabulistas españoles, Tomás de Iriarte. ${ }^{17} \mathrm{La}$ musa del poeta mexicano no le llamaba a cultivar el género didáctico, y por esto sola- 
mente escribió ocho fábulas. Mas ansioso de copiar, de una manera más fiel, a su nuevo modelo, Navarrete se dió a estudiar las formas, los giros $y$ artificios usados por Iriarte, y no pocas veces es feliz en su intento, como podrá notarse en el siguiente soneto, en el cual se puede reconocer el artificio que su modelo usó en su primer soneto:

\section{INFLUJO DE AMOR}

Célebres calles de la corte indiana, Grandes plazas, soberbios edificios, Templos de milagrosos frontispicios, Elevados torreones de arte ufana. Altos palacios de la gloria humana, Fuentes de primorosos artificios, Capiteles, pitámides, hospicios, Que arguyen la grandeza americana. ¡Oh, México! sin duda yo gozara Del gusto que me brinda tu grandeza, Si causa superior no lo estorbara.

De tu suelo me arranca con presteza

El suave influjo de la dulce cara

De una agraciada rústica belleza. 18

Para apreciar la fidelidad con que imitó a Iriarte en este aspecto, ponemos aquí el soneto que le sirvió de modelo:

\section{SONETO PRIMERO}

¿Fresca arboleda del jardín sombrío, Clara fuente, sonoras avecillas, Verde prado que esmaltas las orillas Del celebrado y anchuroso río!

Grata aurora que viertes ya el rocío Por entre nubes rojas y amarillas, Bello horizonte de lejanas villas, Aura blanda que templas el estío.

¡Oh soledad! quien puede te posea; Que yo gozara en tu apacible seno E1 placer que otros ánimos recrea; 
Si tu silencio y tu retiro ameno

Más viva no ofrecieran a mi idea

La imagen de la ingrata por quien peno. 19

Las odas de Navarrete son de poco valor literario, puesto que son tan sólo el primer ensayo de su juventud. Sin embargo, estas composiciones revelan de una manera indiscutible el aprovechado estudio que hizo de Garcilaso y de Lope de Vega. Comparando la primera égloga de Garcilaso ${ }^{20}$ con la primera de Navarrete, ${ }^{21}$ veremos que no sólo los giros poéticos sino asimismo el argumento del poema tienen gran semejanza.

En la égloga de Garcilaso, los personajes son Salicio, Nemoroso y el poeta. En la de Navarrete, Poeta, Mopso y Fenicio. En ambas el poeta pinta la mortal tristeza que embarga el alma del amante. Silicio, en la primera; Fenicio, en la segunda. Los dos revelan la causa de su mortal tristeza, idéntica en ambos: la infidelidad de la pastora amada. El objeto del tercer personaje es también idéntico en ambas composiciones: consolar al pastor infortunado. La única diferencia consiste en el medio de que cada uno se vale para ello. En la primera, Nemoroso deja escuchar sus ayes de dolor, causados por la muerte de su amada. Esta pérdida es irrevocable y por consiguiente mayor que la de Silicio, mientras que en la segunda, Mopso, feliz y satisfecho de la fidelidad de su Dorisa idolatrada, por medio de sabios consejos procura distraer los tristes recuerdos que embargaban el corazón de su amigo Fenicio.

La influencia que Navarrete ejerció en los poetas posteriores, es relativamente leve, sin duda, debido a la brevedad de su carrera literaria. Sus primeras obras aparecieron en el Diario de México, en 1805 , y nuestro poeta murió en 1809. ¡Sólo cuatro años de actividad literaria! $\mathrm{Y}$, sin embargo, numerosas son las composiciones de mérito que dejó a la posteridad. Si el cielo hubiera prolongado su existencia, su influjo habría podido ser inmenso. A pesar de esta circunstancia desfavorable, sabemos que aun antes de la muerte de nuestro amado poeta, Juan Wenceslao Barquera, en una de sus cartas dirigidas al licenciado Carlos Maria Bustamante, tratando de las primeras poesías de Navarrete que aparecieron en el Diario de México, se expresa en los siguientes términos: "En ellas verá usted que el lustre y la belleza de esta facultad no es tan extraña en nuestro clima. Bellas composiciones del buen gusto que interesarán 
nuestros papeles y harán el honor del poeta que me las ha comunicado. Alternarán las mias siguiendo sus propias huellas". ${ }^{22}$ Eso hicie-..ron muchos: seguir las huellas de Navarrete, y por lo mismo, afirmarse en la imitación de Meléndez Valdés que invadió la literatura mexicana.

Otro de sus más fieles discípulos es Sánchez de Tagle. ${ }^{23}$ Imitó a Navarrete no sólo en sus composiciones eróticas y anacreónticas, sino en otras superiores como "El entusiasmo de una noche serena", oda "A la luna en tiempo de discordias civiles", "La melancolía"," "Al Ser Supremo en el día de mis bodas", que indican las tendencias del poeta a la meditación filosófica, siguiendo las huellas del autor de "La Divina Providencia". Los siguientes versos de Sánchez de Tagle nos recuerdan el poema eucarístico de Navarrete. "La Divina Providencia". En ambas composiciones se advierte el mismo fervor religioso y sublimidad filosófica:

AL SER SUPREMO, EN EL DIA DE MIS BODAS

Eterno Ser de Majestad circuido,

Velado por doquier, doquier presente, Mi pecho agradecido

A ti levanta el canto reverente.

¿En dónde estoy? ¿Mi espiritu do vuela?

Yo te miro, gran Dios, ite miro y vivo!

Tus arcanos revela;

Mi humilde fe tu inmensidad percibe.

En un trono de luz tu gloria asientas,

Alli te acata el querubín ardiente:

$Y$ tu poder ostentas

$Y$ emana el ser en vena indiferente.

Bajo tus pies, el tiempo en raudo vuelo

Pasa arrollando deleznables seres:

Pueblan horas el suelo,

$Y$ pasan, y no son: ¿ $Y$ tú ? siempre eres.

Mas otros le suceden al momento:

Ocupa nuevo pie la huella vieja;

$\mathrm{Y}$ en raudo movimiento

Llega el futuro y a vez se aleja.

Tu poder inefable y soberano

El universo sin cesar renueva;

$\mathrm{Y}$ cada ser, ufano,

Al que ha de suceder adentro lleva. ${ }^{24}$ 


\section{LA DIVINA PROVIDENCIA}

Cuando con alas de inmortal deseo

Vuelo hacia todos lados,

Subo y bajo los cielos elevados,

$Y$ tantos seres veo

En su orden respectivo colocados,

Como la luz me guía

De la alma religión, nunca pudiera

Preguntarles dudosa el alma mía,

¿Cuál es el numen misericordioso

Que desde su alta esfera

Cuida de tantos seres amoroso? $\mathbf{2 5}$

Aún más: los árcades, encantados con la hermosura y gracia de las obras de Navarrete, no contentos con elogiar públicamente sus composiciones, le eligieron su Mayoral.

No es, pues, de extrañar que estos poetas se esmeraran en copiar las dotes poéticas con que el cielo había dotado a nuestro poeta.

Sister Adriana Escobar, B. A.

$$
\text { NOTA S }
$$

1 Romera Navarro, Historia de la literatura española, p. 448.

2 Juan Meléndez Valdés nació en Extremadura, en 1754. Estudió en Salamanca y desempeñó varios cargos públicos en España, hasta que la invasión francesa le obligó a ir a Francia donde pasó los últimos años de su vida. Múrió en Montpellier en 1817.

3 Eduardo Gallo, Hombres ilustres mexicanos, p. 152.

4 Ibid.

5 Tesoro del Parnaso español, tomo xv, p. 494.

6 Navarrete, Entretenimientos poéticos, tomo I, p. 219.

7 Marcelino Meléndez Pelayo, Ideas estéticas, tomo III, p. 192.

8 José Iglesias de la Casa nació en Salamanca, en 1753, y falleció allí mismo, en 1791. 
9 Biblioteca de autores españoles, tomo LXI, p. 437.

10 Navarrete, Entretenimientos poéticos, tomo I, p. 125.

11 Nicasio Alvarez de Cienfuegos (1764-1804), nació en Madrid y estudió en Salamanca, al lado de Meléndez Valdés. Por la guerra de la Independencia fué llevado a Francia en rehenes, y falleció al llegar a Ortez. Su tragedia le abrió las puertas de la Academia Española.

12 Biblioteca de autores españoles, tomo LxvII, p. 1.

13 Cueto, Historia de la poesía castellana, tomo II, p. 67.

14 Fray Diego Tadeo González (1733-1794), nació en Ciudad Rodrigo. Tomó el hábito de San Agustín y en esa orden alcanzó diferentes dignidades. Falleció en Madrid.

15 Cueto, Historia de la poesía castellana, tomo I, p. 328.

16 Ibid.

17 Tomás de Iriarte (1750-1787), nació en Tenerife. Hizo sus estudios bajo la dirección de su hermano fray Juan, y más tarde en Madrid, bajo la dirección de su tío Juan Iriarte, a quien sucedió en el empleo oficial de traductor de la primera Secretaría del Estado en Madrid, donde murió.

18 Navarrete, Entretenimientos poéticos, tomo I, p. 281.

19 Quintana, José Manuel, Tesoro del Parnaso, p. 466.

20 Ibid., p. 41.

21 Navarrete, Entretenimientos poéticos, tomo I, p. 233.

22 Justo Sierra, Antología del Centenario. Estudio preliminar, p. xxv.

23 Francisco Manuel Sánchez de Tagle nació en la ciudad de Morelia, en 1782. En 1787 la familia se trasladó a México y Francisco Manuel recibió su educación en el colegio de San Juan de Letrán. Después de haber desempeñado varios cargos públicos de importancia, murió en 1847 .

24 Sánchez de Tagle, Obras poéticas, tomo I, p. 90.

25 Navarrete, Eniretenimientos poéticos, tomo II, p. 203. 